\title{
The Acceptance Model of M-Payment Using Smartphone Devices in Thailand: A Conceptual Framework
}

\author{
Parisgawin Nakwari ${ }^{1}$, Worapoj Kreesuradej ${ }^{1}$ and Singha Chaveesuk ${ }^{2+}$ \\ ${ }^{1}$ Faculty of Information Technology, King Mongkut's Institute of Technology Ladkrabang, \\ Bangkok, Thailand \\ ${ }^{2}$ Faculty of Administration and Management, King Mongkut's Institute of Technology Ladkrabang, \\ Bangkok, Thailand
}

\begin{abstract}
In this paper, we have proposed the M-payment method using the smartphone applications, from which all electronic transactions such as purchasing, sales and the provision of other financial services can be applied. This is the investigation of the UTAUT2 extended theory that can be more appropriate for the consumers. The UTAUT2 extended theory is integrated with the service quality, which can be used to examine the acceptance potential of the M-Payment user by smartphone devices. The outcomes of this study will benefit the financial industry in their effort to initiate an extensive online-payment process in all users, especially, in Thailand.
\end{abstract}

Keywords: M-Payment, Digital transactions, UTAUT2, Service quality, PIIT

\section{Introduction}

The current information technology has aimed to the digital era, where all data transaction is gone under the online platforms [1]. All sectors, especially the government departments have also laid out a digital economy policy, which has as its main concept that the applied usage of information and communication technology (ICT) with economic activity is implemented to increase the efficiency and competitiveness of the country, which is particularly relevant to areas such as internet banking, electronic commerce, and mobile payment. The Mobile-Payment is a process of digital economic activity that includes electronic transactions in the purchase, sale or provision of services by smartphone devices [2], where a common type of M-Payment is the operational network that links bank accounts and provides for monetary exchange using bank deposits [3]. Currently, the efficient digital-payments reduces the cost of operations and it is easy to manage transactions of the interbank, money, and capital markets.

However, the acceptance of M-Payment by the smartphone devices is still unclear, where the focus on the user perception of the technology may not be enough. The aspects such as service quality (personal innovativeness, customer service, application, and trust) are considered as the main factor that will affect internet users' willingness to use online transactions, which includes the performance expectancy, effort expectancy, social influence and facilitating conditions. Many consumers are not willing to use online transactions as they are concerned about security risks on the internet [4]. In other words, when tasks become more financially complex, technologies will be struggled to meet the task demands [5]. This risk could affect user acceptance.

Therefore, this study intends to examine consumer behaviour on the M-Payment acceptance using the smartphone devices by UTAUT2, where the integration with the service quality explains the variance of user

\footnotetext{
${ }^{+}$Corresponding author. Tel.: + 662-329-8460; fax: +662-329-8461.
}

E-mail address: singha@it.kmitl.ac.th. 
acceptance. In addition, this study will consider the acceptance of M-Payment with the intention of enabling them to develop their business in future.

\section{Theoretical Foundation}

To discuss the user intentions in using a new technology, prior researchers developed several models such as Technology Acceptance Model (TAM), diffusion of innovation (DOI), UTAUT and UTAUT2. However, most of the prior studies associated with M-Payments adopted TAM to understand user acceptance of a new technology [6], [7], [8]. Although TAM is a useful model in the prediction of user acceptance, the perceived usefulness and ease of use do not consider the applicability of the technology and the objective usefulness. Therefore, this study applies UTAUT2 to explore factors that influence consumer intentions of using M-Payments [9], [10], [11].

\subsection{Extending the Unified Theory of Acceptance and Use of Technology}

According to research of [12] shown the UTAUT2 was modified from the Unified Theory of Acceptance \& Use of Technology [13] to explain about consumer behaviour towards technology, the UTAUT has four factors (Performance Expectancy, Effort Expectancy, Social Influence and Facilitating Conditions) which influence behavioural intentions in the use of technology. Besides that, when UTAUT and UTAUT2 are compared, it becomes clear that UTAUT2 includes the three factors (hedonic motivation, price value and habit) and uses moderator variables such as gender, age and experience. The constructs of UTAUT2 and the definitions of each construct are listed as shown in the previous discussion [8].

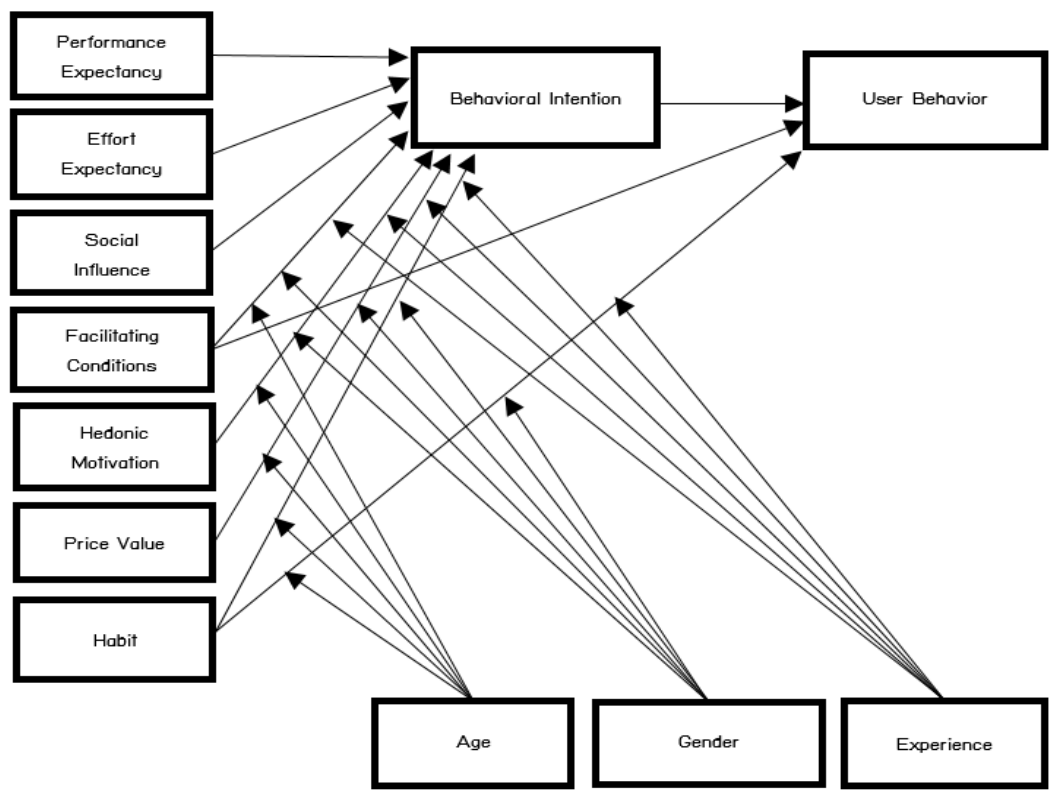

Fig. 1: The model of UTAUT2.

\subsection{Service Quality}

The service quality happens to be recognised and extensively utilised in evaluating M-Payment service quality. Customer service quality was linked to product assortment and the varied characteristics of the service outcomes [14]. In 2003, DeLone and McLean [15] proposed an updated information system (IS) success model in which the service quality construct influences IT use (or intention to use) directly or indirectly through user satisfaction. With the advent of the Internet, there was a shift from the organizational environment to the online environment, and from the IS users to the e-services users. Consequently, service quality represents not only the technical issues of the IT but also the support delivered by the technology [15]. Choudhury [16] emphasizes the point that service quality is a multifaceted and multidimensional concept. The service quality dimensions recognised in this investigation, according to [15], [17], [18] are trust, personal innovativeness, application design, and customer service.

- Trust is a subjective belief that a party will fulfil their obligations and it plays an important role in uncertain financial transactions where users of the system are vulnerable to financial loss [19], [20]. 
In addition, trust is even more important in electronic transactions, which are characterised by anonymity and lack of social cues due to spatial separation [21]. Trust can help to reduce high perceptions of risk as trust helps users to overcome the uncertainty or anxiety of the behaviour and its possible outcomes [22].

- Personal innovativeness in the domain of information technology (PIIT) is defined as "the willingness of an individual to try out any new information technology" [23]. PIIT is a recent construct in the innovation adoption literature as defined by [23] as a trait-oriented abstract construct that is relatively invariant across situational considerations. These authors hypothesized that PIIT will moderate the effect of key perceptions about a new IT (relative advantage, ease of use, and compatibility) on the intentions to use a new IT [24].

- Application design is very simple design and clarity, visibility and navigability for customers to be able to easily operate. Because if people believe that they will benefit from a high quality application, not only will they use the application, but they will also raise their evaluations of its usefulness [25].

- Customer service is considered crucial for success and survival in today's competitive market. But it is also important to understand what contributes to customer satisfaction that could be a key to the intension to use M-Payment.

\section{Conceptual Framework and Hypothesis Development}

In order to study the factors that affect user intention of M-Payment by a smartphone device, this study establishes the proposed model based on the UTAUT2 theory. Although the UTAUT model proposed in the background of organizational adoption has relatively good explanatory power, it's not perfectly suitable for online payment [26]. However, a recent study suggests integrating different models to get a more comprehensive view of achieving the objectives of the research [27]. Therefore, this study will integrate UTAUT2 with Service quality. The final model is shown in Figure 2.

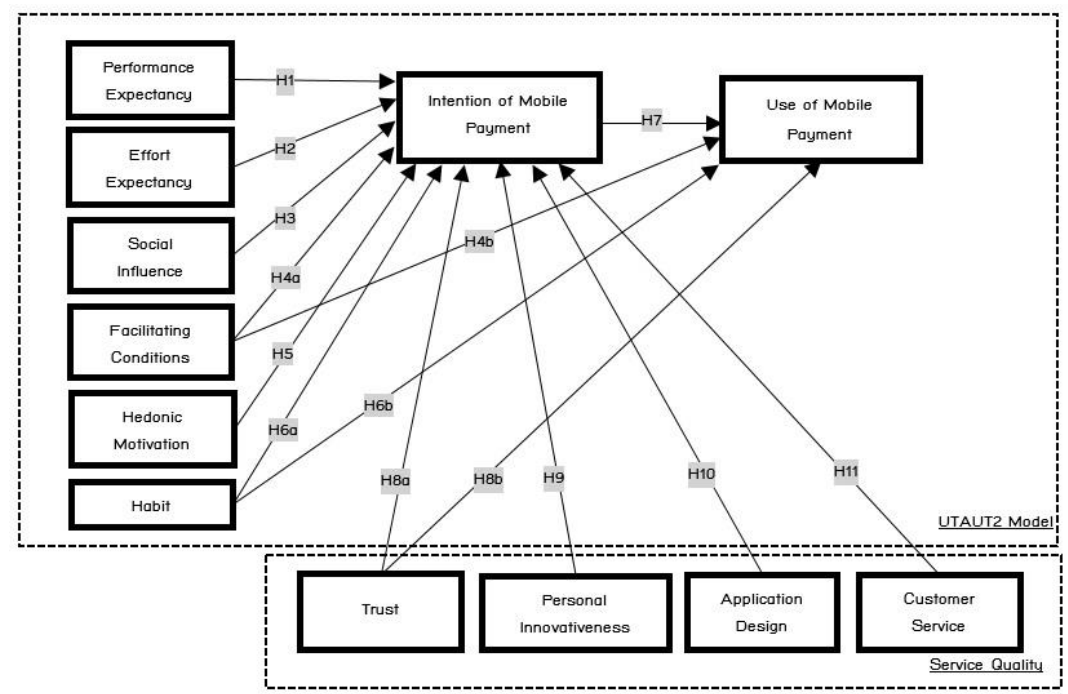

Fig. 2: Conceptual framework.

Based on the original UTAUT2 model, the factor performance expectancy, effort expectancy, social influence, facilitating conditions, hedonic motivation, price value, and habit will be applicable to find the acceptance of M-Payment users in Thailand. However, age, gender and experience were not applicable in the model because M-Payment in Thailand is a new technology that the government is trying to push. Users do not have experience in the use of this system [2]. In addition, the construct of price value was not including in the conceptual framework model. Because the usage of M-Payment was sent to the user who already uses smartphones, there would not be any cost occurred as they use digital payment services by smartphone devices [8].

Performance expectancy describes a user's belief that the use of M-Payment provides many benefits such as convenient payment, efficient payment and fast response [28]. Effort expectancy explains that M-Payment 
user perceptions did not find difficulties in using the M-Payment system such as ease of use, ease of learning and ease of understanding [29]. Social influence includes social factors relating to close family and friends which can influence others in the use of M-Payment [28], [30]. Facilitating conditions reflect the effect of a user's knowledge, ability and resources such as an Internet connection, device support, the availability of the M-Payment application, knowledge and skills as well as other factors that are needed to operate the MPayment [13], [28]. Hedonic motivation explains about fun or pleasure derived from using M-Payment [31]. Habit reflects the user's behaviour regarding M-Payment in daily life. The intention of M-Payment is used to describe the desire of users to use M-Payment. While the Use of M-Payment is used to describe the intensity of use of M-Payment in daily life [28]. In previous research, these six factors included Performance Expectancy [8], [11], [32]. Effort expectancy [33], [34], [35] Social influence [9], [11], [36] Facilitating conditions [14], [32], [35]. Hedonic motivation [8], [9], [10] and Habit [11], [12], [32] have significant impact in the study of acceptance factors for M-Payment services. Therefore this study hypothesized the following:

H1: Performance Expectancy positively affects the Intention of M-Payment to accept M-Payment.

H2: Effort Expectancy positively affects the Intention of M-Payment to accept M-Payment.

H3: Social Influence positively affects the Intention of M-Payment to accept M-Payment.

H4a: Facilitating Conditions positively affects the Intention of M-Payment to accept M-Payment.

H4b: Facilitating Condition positively affects the Use of M-Payment to accept M-Payment.

H5: Hedonic Motivation positively affects the Intention of M-Payment to accept M-Payment.

H6a: Habit positive positively affects the Intention of M-Payment to accept M-Payment.

H6b: Habit positive positively affects the Use of M-Payment to accept M-Payment.

H7: Intention of M-Payment positively affects the Use of M-Payment to accept M-Payment.

In the research model (fig. 2), service quality is added to the UTAUT2 model to explain the continued use of M-Payment. The conceptualization of service quality that includes trust, according to [14], [22], [28], reflects the function of the degree of risk involved in financial transactions, and the outcome of trust is reduced perceived risk, leading to positive intentions toward M-Payment adoption. Personal innovativeness reflects the influence of beliefs or perception (ease of use and usefulness) about the use of information technology, it was argued, based on Agarwal and Prasad (1998)'s study [23], that individual with higher PIIT are expected to develop more positive beliefs about the target technology and this postulation has gained empirical support [18]. From [17] and [18] found that PIIT has the significant positive impact on both ease of use and usefulness. According to [13], [25], [37], the application design reflects the key approach to ensure the application meets visitor's needs to adopt M-Payment. According to [17], [15], [38], customer service reflects the responsive, helpful, willing service that responds to customer inquiries quickly. Therefore this study hypothesized the following:

H8a: Trust positively affects the Intention of M-Payment to accept M-Payment.

H8b: Trust positively affects the Use of M-Payment to accept M-Payment.

H9: Personal Innovativeness affects the Intention of M-Payment to accept M-Payment.

H10: Application design positively affects the Intention of M-Payment to accept M-Payment.

H11: Customer service positively affects the Intention of M-Payment to accept M-Payment.

\section{Contributions}

This study is a proposed model of the M-Payment acceptance using the smartphone devices, especially, in Thailand based on the UTAUT2 integrated service quality. The obtained result of this study is shown that the create an efficient structure can be explored by the M-Payment acceptance of the smartphone devices. Furthermore, the study on this topic is necessary which will be continued. The data will be collected from the people (Thai users) through the designed questionnaires, where the determinants of the research model and structural equation modelling will be investigated. This model will provide a useful tool to understand and predict the user's intention to accept M-Payment using smartphone devices in Thailand. 


\section{References}

[1] THAILAND board of investment. Thailand Investment Review. Bangkok, 2016.

[2] Chaluay, P., Chaveesuk, S., Pantuwong, N. The acceptance model of a national e-payment in Thailand: Conceptual framework. 7th International Workshop on Computer Science and Engineering, 2017, 1302-1307.

[3] J. Summers. Payment Systems: Design, Governance and Oversight. Central Banking Publications Ltd. 2012: 3.

[4] Chung-Hung Tsai, Dauw-Song Zhu, and Yueh-Meei Jang. A study on the consumer adoption behaviors of Internet banks. Proc. of Computer and Information Science (ICIS). Niigata. 2013, 263-268.

[5] Dishaw, M. T., and Strong, D. M. Extending the technology acceptance model with task-technology fit constructs. Information \& Management. 1999, 36: 9-21.

[6] Nguyen, T.P.L.; Seddaiu, G.; Virdis, S.G.P.; Tidore, C.; Pasqui, M.; Roggero, P.P. Perceiving to learn or learningto perceive? Understanding farmers' perceptions and adaptation to climate uncertainties. Agric. Syst. 2016, 143: 205-216.

[7] A. Y. L. Chong, F. T. Chan, and K. B. Ooi. Predicting consumer decisions to adopt mobile commerce: Cross country empirical examination between China and Malaysia. Decision Support Systems. 2011, 53(1): 34-43.

[8] L.Y. Ming and L.T. Yin. The college students' behavior intention of using mobile payments in Taiwan: An exploratory research. Proceedings of IASTEM International Conference, Singapore. 2017: 2-6.

[9] Tiago Oliveira, Manoj Thomas, Goncalo Baptista and Filipe Campos. Mobile payment: Understanding the determinants of customer adoption and intention to recommend the technology. Computers in Human Behavior, 2016, 61: 404-414.

[10] Paddy Mugambe. UTAUT Model in Explaining the Adoption of Mobile Money Usage by MSMEs' Customers in Uganda. Advances in Economics and Business, 2017, 5(3): 129-136.

[11] Cristian Morosan and Agnes DeFranco, It's about time: Revisiting UTAUT2 to examine consumers' intentions to use NFC mobile payments in hotels. International Journal of Hospitality Management, 2016, 53: 17-29.

[12] V. Venkatesh, J. Y. Thong, and X. Xu. Consumer acceptance and use of information technology: extending the unified theory of acceptance and use of technology. MIS quarterly. 2012, 36(1): 157-178.

[13] V. Venkatesh, M. G., Morris, G. B. Davis, and F. D. Davis. User acceptance of information technology: Toward a unified view. MIS quarterly. 2003, 27(3): 425-478.

[14] TC. Okeke, GA. Ezeh and NOA. Ugochukwu. Service Quality Dimensions and Customer Satisfaction with Online Services of Nigerian Banks. Journal of Internet Banking and Commerce, 2015, 20(3).

[15] Moteb ALBUGAMI and Moez BELLAAJ. The continued use if internet banking: combining UTAUT2 theory and service quality model. Journal of Global Management Research, 2014: 11-27.

[16] Choudhury K . Service Quality Dimensionality: A Study of the Indian Banking Sector. Journal of Asia-Pacific Business, 2007, 8: 21-38.

[17] Zeitham Valarie A. 1, Parasuraman A. and Malhotra Arvind . Service Quality Delivery Through Web Sites: A Critical Review of Extant Knowledge. Journal of the Academy of Marketing Science, 2002, 30(4): 362-375.

[18] Noel Y.M. Siu and Ludwig, M.K. Chang. A Study of service quality, perceived risk and personal innovativeness in internet banking. Revolution in Marketing: Market Driving Changes, 2014: 78-83.

[19] Lu, Y., Yang, S., Chau, P. \& Cao, Y. Dynamics between the trust transfer process and intention to use mobile payment services: A cross-environment perspective. Information \& Management, 2011, 48(8): 393-403.

[20] Gefen, D., Karahanna, E. \& Straub, D. Trust \& TAM in online shopping: An integrated model. MIS Quarterly, 2013, 27(1): 51-90.

[21] Zhou, T. Examining mobile banking user adoption from the perspectives of trust and flow experience. Information Technology \& Management, 2012, 13(1): 27-37.

[22] Emma Slade, Michael Williams and Yogesh Dwivdei. Extending UTAUT2 to explore consumer adoption of mobile payments. UK Academy for Information Systems Conference Proceedings, 2013.

[23] Agarwal, R., and Prasad, J. A Conceptual and Operational Definition of Personal Innovativeness in the Domain of Information Technology, Information Systems Research (9:2) 1998: 204-215. 
[24] Rajiv Kishore and Ephraim McLean. The role of personal innovativeness and self-efficacy in information technology acceptance: an extension of TAM with notions of risk. International Conference on Information Systems, 2011: 469-474.

[25] Al-Qeisi K, Dennis C, Alamanos E, Jayawardhena C. Website design quality and usage behavior: Unified Theory of Acceptance and Use of Technology. Journal of Business Research, 2014, 67(11): 2282-2290.

[26] Jie Gu, Heng Xu, and An'an Hu. Exploring the effect of permission notice on users' initial trust to an application store: The case of China's Android application market. International Conference on Intelligence and Security Informatics (ISI). 2015: 67-72.

[27] Ir. Listyo Dwi Harsono and A.S. Lisandy. Factors affecting the use behavior of social media using UTAUT2 Model. AP14Singapore Conference, Singapore, 2014.

[28] Tao Zhou, Yaobin Lu, and Bin Wang. Integrating TTF and UTAUT to explain mobile banking user adoption. Computers in Human Behavior. 2010, 26(4): 760-767.

[29] Lopez-Nicolas C., Molina-Castillo F. J., and Bouwman H. An assessment of advanced mobile services a cceptance:Contributions from TAM and diffusion theory models. Information \& Management. 2008, 45(6): 359364.

[30] Brown, S. A., and Venkatesh, V. Model of Adoption of Technology in the Household: A Baseline Model Test and Extension Incorporating Household Life Cycle, MIS Quarterly(29:4), 2005: 399-426.

[31] Yousafzai, S.Y., Pallister, J.G. and Foxall, G.R. A proposed model of e-trust for electronic banking. Technovation, 2003, 23(11): 847-860.

[32] Numan $r$ manaf and Maya ariyanti. exploring key factors on technology acceptance of mobile payment users in Indonesia using modified unified theory of acceptance and use of technology (UTAUT) model use case: abc easy tab. International Journal of Management and Applied Science, 2017, 3(1).

[33] Adelyn Kuan Lai Kit, ann hui ni, Emeilee Nur Freida Binti Mohd BadriI and Tang Kia Yee. UTAUT2 influencing the behavioural intention to adopt mobile application to adopt mobile applications. Bachelor of Commerce (HONS) Accounting, Universititunku Abdul Rahman, 2014.

[34] Mohammad Abdullah Mahfuz, Liza Khanam and Dr.Selvarasu Appasamy. The Influence of Website Quality on m-banking Services Adoption in Bangladesh: applying the UTAUT2 model using PLS. International Conference on Electrical, Electronics, and Optimization Techniques (ICEEOT), 2016: 2329-2355.

[35] Ali Abdallah Alalwan, Yogesh K. Dwivedi and Nripendra P. Rana. Factors influencing adoption of mobile banking by Jordanian bank customers: Extending UTAUT2 with trust. International Journal of Information Management, 2017, 37: 99-110.

[36] Simon Megadewandanu, Suyoto and Pranowo. Exploring Mobile Wallet Adoption in Indonesia Using UTAUT2. 2016 2nd International Conference on Science and Technology - Computer (ICST), Yogyakarta, Indonesia, 2016: 1-6.

[37] Igbaria, M., Iivari, J. \& Maragahh, H. Why do individuals use computer technology? A Finnish case study. Information \& Management. 1995, 29: 227-238.

[38] Wolfinbarger M. and Gilly C. eTailQ: dimensionalizing, measuring and predicting etail quality. Journal of Retailing , 2003, 79: 183-198. 